\title{
INVESTIGACIONES
}

\section{Contarte. Una sistematización de la práctica reflexiva entre docente y amiga crítica}

\author{
Contarte. A sistematization of the reflective practice \\ between teacher and critical friend
}

\section{María de la Luz Marqués Rosa $a^{a}$ Fabiola Georgina Molina Hernández, Viviana de Lourdes Gómez Nocetti ${ }^{a}$, Macarena Belén Angulo Carmona ${ }^{c}$}

\author{
${ }^{a}$ Pontificia Universidad Católica de Chile, Campus Villarrica. \\ mamarques@uc.cl,vgomezn@uc.cl \\ ${ }^{b}$ Fundación Ilumina, Chile. \\ fabimolinah5@gmail.com \\ ${ }^{c}$ Universidad de Santiago de Chile. \\ macarena.angulo@usach.cl
}

\section{RESUMEN}

Superar los obstáculos que pueden presentarse en el aprendizaje de la lengua, especialmente en niños que viven en contextos de pobreza, demanda intervenciones a temprana edad y docentes con una alta capacidad reflexiva. Se presenta la Sistematización de una Experiencia denominada Contarte con el objeto de documentar la práctica educativa en el nivel inicial y dar valor agregado a la reflexión colaborativa entre docente y amiga crítica durante el proceso de enseñanza-aprendizaje. Los hallazgos muestran que los niveles de complejidad en el desempeño de los niños son crecientes en tanto que docente y amiga crítica se retroalimentan de manera permanente en pos del mejoramiento de esta experiencia educativa. Se releva el esfuerzo reflexivo por parte del docente como herramienta transformadora de la realidad injusta que no ofrece a todos los niños las mismas oportunidades para el desarrollo de competencias comunicativas.

Palabras claves: Sistematización de experiencias, reflexión colaborativa, retroalimentación, amigo crítico, desarrollo profesional docente.

\section{ABSTRACT}

To overcome the obstacles that may show up in the language learning process, especially in children who live in poverty contexts, demands interventions at an early age and teachers with a high reflective capacity. The Systematization of an Experience called Contarte is presented in order to document educational practice at the initial level and add value to collaborative reflection between teacher and critical friend during the teachinglearning process. Findings show that the complexity levels in children's performance increase as teachers and critical friends continuously feedback in pursuit of the improvement of this educational experience. The reflective effort on the part of the teacher is highlighted as a transforming tool of the unfair reality that does not offer the same opportunities for the development of communicative skills to all children.

Key words: Experience systematization, collaborative reflection, feedback, critical friend, teachers' professional development. 


\section{INTRODUCCIÓN}

La literatura especializada es consistente en afirmar que los niños y niñas (en adelante niños) de sectores desfavorecidos cuentan con pocas oportunidades para el desarrollo de competencias comunicativas (Hart y Risley, 1995; Evans, 2004; Pujato, 2011). Chile no escapa a esta realidad, a pesar de posicionarse en el primer lugar en cuanto a logros educacionales en Latinoamérica según un informe emitido por el Programa de las Naciones Unidas Para el Desarrollo (PNUD, 2017). Como muestra el informe Desiguales, existe un alto nivel de desigualdad en las competencias lectoras según nivel socioeconómico (NSE), encontrándose muy por detrás en el ranking de los países de la OCDE, lo cual impacta en el futuro laboral de las personas (PNUD, 2017; Eyzaguirre y Fontaine, 2008). Los resultados obtenidos por Sistema de Medición de la Calidad de la Educación (SIMCE) ${ }^{1}$ 2018, reveló que los alumnos de NSE bajo $4^{\text {to }}$ y $6^{\text {to }}$ año básico se encuentran 50 puntos por debajo de sus pares de NSE alto en el área del lenguaje (Agencia de Calidad de la Educación, 2019a), diferencia que aumenta a 55 puntos en la región donde se realizó este estudio (Agencia de Calidad de la Educación, 2019b).

Eyzaguirre y Fontaine (2008) investigaron qué factores internos a la escuela afectaban el rendimiento de los niños, comparando escuelas del NSE medio bajo, con diferentes logros en el SIMCE (alto, medio y bajo). Las autoras encontraron que en Kinder las escuelas de SIMCE alto ocupaban hasta 30 minutos diarios en actividades relacionadas con lectura (escuchar lectura y actividades de pre-lectura ${ }^{2}$ ) y en primer año básico todos los niños eran capaces de leer. En cambio, en las escuelas de SIMCE bajo se dedicaban entre 6 y 12 minutos exclusivamente a pre-lectura y en primero básico un $25 \%$ de los niños no lograban leer. Las autoras advirtieron que, a pesar de que las escuelas con alto SIMCE obtuvieron mejores logros, en segundo básico, los establecimientos de elite las aventajaban en dos años de escolaridad (Eyzaguirre y Fontaine, 2008).

Asimismo señalan que en las escuelas de SIMCE bajo se leían cuentos menos de tres veces a la semana; se realizaban menos ejercicios de conciencia fonológica, lectura y escritura; se leían y escribían solo vocales; los niños habitualmente no escuchaban, por lo que las instrucciones se repetían individualmente; al comentar cuentos las preguntas se dirigían al grupo en general; las expectativas eran más bajas; no se alentaba a un trabajo ágil ni bien acabado; no se exigían respuestas individuales ni trabajo independiente y la mayor parte del tiempo escolar se dedicaba a las rutinas (comer, ir al baño, vestirse, saludar) (Eyzaguirre y Fontaine, 2008).

Resulta pertinente preguntarse entonces, ¿cómo se pueden transformar las situaciones de desigualdad presentes en el contexto nacional si no se ofrecen a todos los niños las mismas oportunidades para asignar sentido y significado al mundo letrado en la interacción oral con otros? (Rosas y Santa Cruz, 2013).

SIMCE es una evaluación de aprendizaje que aborda el logro de los contenidos y habilidades del currículo vigente en diferentes asignaturas y áreas de aprendizaje, y que se aplica a todos los estudiantes del país que cursan los niveles evaluados. Integra además los Cuestionarios de Calidad y Contexto, respondidos por estudiantes, docentes, padres y apoderados, que recogen información del entorno escolar y familiar de los estudiantes con el objeto de contextualizar los resultados obtenidos por estos en las diferentes pruebas.

2 Normalmente las actividades de prelectura consistían en reconocer nombre y sonido de las letras aisladas o dentro de una palabra, parear letras o palabras iguales, reconocer palabras aisladas o dentro de una frase. 
Se requieren, entonces, intervenciones a más temprana edad para superar los obstáculos en el aprendizaje de la lengua oral y escrita, especialmente de niños que viven en contextos de pobreza (Rosas y Santa Cruz, 2013). La normativa vigente (Subsecretaría para la Educación Parvularia, 2018), asigna a las educadoras de párvulos la responsabilidad de introducir a los niños en la literacidad, abordando aspectos lingüísticos, sociales y afectivos en su aprendizaje. Estas acciones requieren ser realizadas por docentes con una alta capacidad reflexiva (Giroux, 1997; Zeichner y Liston, 2014), capaces de considerar los distintos elementos del contexto donde ejercen su labor formadora, para problematizar en torno a estos haciendo dialogar la experiencia y la teoría.

Este artículo presenta la sistematización de una experiencia (SE), en un intento por responder a estas demandas en una escuela pública bidocente ubicada en el sector rural en el sur de Chile. En esta escuela, la educadora de párvulos creó, implementó y produjo mejoras en un proyecto pedagógico-didáctico titulado Contarte, a partir de procesos reflexivos acompañados por una amiga crítica.

El objetivo de Contarte fue mejorar las competencias comunicativas de los niños a través de la interacción mediada con textos poéticos, la conversación literaria, el juego y la representación visual, de modo de incorporar prácticas de enseñanza-aprendizaje que apuntaran a brindar igualdad de oportunidades.

\section{NOCIONES CONCEPTUALES}

En las siguientes secciones se abordarán las nociones conceptuales que enmarcan esta experiencia, a saber: la práctica reflexiva como una alternativa para el desarrollo profesional docente, la reflexión colaborativa propiciada por una amiga crítica y los distintos niveles de reflexión propuestos por la investigación.

\subsection{PAPEL DE LA PRÁCTICA REFLEXIVA EN EL DESARROLLO PROFESIONAL DOCENTE}

Los programas de desarrollo profesional docente tradicionales han sido criticados porque promueven un rol pasivo en el profesor, porque pasan por alto su agencia y por su vaga conexión con el mejoramiento de la enseñanza y el aprendizaje de los alumnos (Timperley, 2011). Es necesario hacer un cambio fundamental permitiendo que los profesores se comprometan en una indagación sistemática del aula (Wennergren, 2016).

Aunque existen diversas definiciones sobre "práctica reflexiva" y no hay consenso sobre cómo llevarla a cabo (Mena, Sánchez y Tillema, 2011), se observa cierto acuerdo en torno a su potencial transformador de las creencias sobre el proceso de enseñanzaaprendizaje (Cephe, 2009; Lotter y Miller, 2017) y, por consiguiente, sobre su importancia en la práctica docente y en los programas de formación de profesores (Abou, 2007; Schön, 2017; Zeichner y Liston, 2014).

Donald Schön relevó la importancia de la conversación reflexiva en el proceso de enseñanza-aprendizaje hace varias décadas (Schön, 1987; Schön, 1993), proponiendo la reflexión como una alternativa a una epistemología de la "racionalidad técnica", en la que los profesionales eran vistos como expertos en conocimientos, limitados a responder solo a problemas tipo (Schön, 2017). Manifestó la necesidad de alejarse de dicho enfoque porque divorciaba artificialmente la teoría y la práctica, sugiriendo que los profesionales 
debieran transformarse en investigadores en los contextos de práctica, a partir de los cuales desarrollar sus conocimientos y su comprensión a través de la acción. Así pasarían de ser receptores de información a productores activos de conocimiento (Wennergren, 2016).

Farrell (2007) aportó la siguiente definición de "práctica reflexiva":

[Es] una aproximación bottom-up al desarrollo profesional docente que se basa en la creencia de que los profesores, tanto experimentados como noveles, pueden mejorar la comprensión de su propia enseñanza reflexionando sistemática y conscientemente en sus experiencias de enseñanza (p. 9).

Esta práctica tiene gran valor profesional pues a través de ella el docente "recoge datos sobre su enseñanza y examina sus actitudes, creencias, asunciones y prácticas docentes, usando esta información obtenida como base para la reflexión crítica sobre ella" (Richards y Lockhart, 1994, p. 131), abriendo la posibilidad de reformular la práctica (Korthagen, Kessels, Koster, Lagerwerf y Wubbels, 2001) lo que acentúa la agencia de los docentes (Timperley, 2011).

\subsection{EL "AMIGO CRÍTICO" COMO FACILITADOR DE LA REFLEXIÓN}

No obstante, tomar decisiones individualmente presenta una subjetividad difícil de suprimir. Por esto, Çimer, Odabași y Sezen (2013) destacaron la necesidad de contar con otras personas con quienes realizar dicha reflexión, los denominados "amigos críticos" (Aktekin, 2019; Beveridge, Mockler y Gore, 2017; Day, 1999; Golby y Appleby, 1995; Gurr y Drysdale, 2018).

A diferencia de la figura del profesor mentor, quien es un docente experimentado que interactúa con uno principiante para desarrollar elementos pedagógicos, competencias comunicativas y análisis reflexivo de la práctica (Gorichon et al., 2020), el amigo crítico es un oyente atento y reflexivo, un profesional visionario y articulado que fomenta la recolección de datos y la indagación para reformular la práctica actual (Hill, 2002) desde una relación horizontal que establece con su par. Swaffield (2005) señaló que los factores que contribuyen a una amistad crítica efectiva son confianza, valores y propósitos compartidos, cualidades personales, comunicación y acción práctica.

La investigación muestra abundante evidencia de su efectividad para desarrollar la capacidad reflexiva sobre el ejercicio docente, transformándose en un componente central de las comunidades de aprendizaje profesional situadas en instituciones escolares (Aktekin, 2019; Swars, Meyers, Schafer, Kavanagh y Haardoefer, 2018; Wennergren, 2016).

El tipo de reflexión que utiliza es la "reflexión guiada", donde la enseñanza reflexiva es un proceso de resolución de problemas (Cole, 2012) que combina la teoría de la disonancia cognitiva propuesta por Piaget con la teoría del aprendizaje por rendimiento asistido en la Zona de Desarrollo Próximo (ZDP), propuesta por Vygotsky (Risko, Vukelich y Roskos, 2009). Así, en un proceso de desarrollo, en el cual la interacción social es clave para "dar sentido" (Petroelje, Frambaugh-Kritzer, Freese y Persson, 2018), el amigo crítico apoya la enseñanza contribuyendo con una comprensión más profunda, encontrando al colega en su ZDP (Wennergren, 2016).

Respecto a la amistad crítica como actividad reflexiva, Petroelje, Frambaugh-Kritzer, Freese y Persson (2018) observan tres elementos que proponen como centrales para su 
efectividad. La vulnerabilidad en primer lugar, refiriéndose a que, como amigos cercanos, las personas se sienten más dispuestas a tomar el riesgo dar y recibir una crítica fuerte; la reflexión, al moverse entre el descubrimiento personal y un pensamiento colectivo al reflexionar colaborativamente; y el escepticismo, elemento relativo a la formulación recurrente de preguntas que pueden ser útiles para lograr una mayor claridad en lo abordado por aquellas personas comprometidas en esta amistad crítica.

Otras investigaciones recientes se refieren a las consecuencias de una retroalimentación constructiva entre docentes (Fen, Sam y Meng, 2017; Loh, Hong y Koh, 2018) señalando que produce un efecto similar al que ocurre entre los estudiantes: desarrollan la capacidad de tomar decisiones para adaptar su práctica y así satisfacer las necesidades de sus alumnos, así como también pueden analizar su trabajo y reconstruir sus conocimientos profesionales y personales (Lotter y Miller, 2017).

\subsection{NIVELES DE REFLEXIÓN DOCENTE. EL MODELO DE LARRIVEE}

Las capacidades desarrolladas tras el proceso reflexivo pueden ser analizadas en "niveles de reflexión". En la literatura disponible existen varios modelos para encasillar el nivel de profundidad de los docentes en tareas de reflexión (Arredondo, Beas, Gómez, Thomsen y Carranza, 2009; Hatton y Smith, 1995; Jay y Johnson, 2002; Larrivee, 2008; SparksLanger y Colton, 1991; Van Manen, 1977; Zeichner y Liston, 1985).

Para nuestro análisis, optamos por el modelo de Larrivee (2008), quien propone una gradualidad de cuatro niveles; sin perjuicio de que el docente pueda encontrarse en diferentes niveles de forma simultánea (Larrivee, 2008); estos niveles son:

- Pre-reflexión: el docente cree que las contingencias situacionales escapan de su control, sus posturas y creencias sobre las necesidades de sus estudiantes y sobre la enseñanza son generalizadas y carecen de fundamento experiencial, teórico o empírico.

- Reflexión superficial: el docente limita su análisis de los métodos de enseñanza a asuntos técnicos respecto a cómo lograr objetivos y estándares predeterminados; sus creencias y posturas sobre las prácticas de enseñanza se basan en la experiencia y no en fundamentos teóricos o empíricos; reconoce la necesidad de la diversidad de sus estudiantes, pero no es capaz de ajustar su práctica a estas.

- Reflexión pedagógica: el docente piensa constantemente en cómo sus prácticas de enseñanza afectan el aprendizaje de sus estudiantes y en cómo mejorar las experiencias de aprendizaje para todos ellos; las creencias y posturas sobre la enseñanza son específicas y se basan en fundamentos experienciales, teóricos y empíricos, alcanzando una mirada multidimensional del proceso enseñanzaaprendizaje que le ayuda a asociar hechos en un marco más amplio.

- Reflexión crítica: el docente está comprometido con la práctica reflexiva y la investigación crítica de la enseñanza y los procesos de pensamiento. En este nivel se sostienen ideologías filosóficas y prácticas de enseñanza en continua examinación y verificación, lo que implica consciencia sobre cómo las creencias, valores personales, supuestos, la impronta familiar y el condicionamiento cultural pueden afectar a los estudiantes, además de promover ideales democráticos y sopesar las implicaciones éticas y sociales de las prácticas en el aula. 
Según este enfoque, el acompañamiento es fundamental para promover una práctica reflexiva que evolucione de lo más simple a lo más complejo,

la mejora de la calidad reflexiva debe ser concebida como un proceso constante y en "capas" o en espiral, donde los profesores, especialmente los noveles, deben ser acompañados por profesores más experimentados en un ambiente que genere seguridad y soporte emocional (Larrivee, 2008, p. 345).

Gómez, Guerra, Santa Cruz, Thomsen, Rodríguez y Beas (2012) demostraron que los docentes que eran acompañados o retroalimentados por un par avanzaron más rápidamente hacia niveles reflexivos más complejos, comparado con quienes tuvieron experiencias de reflexión guiadas únicamente por libretos. Esto demuestra que los niveles de reflexión están estrechamente relacionados con la retroalimentación recibida de otro más experto que apoya y desafía al docente (Baskerville y Goldblatt, 2009; Black y Wiliam, 2009; Hattie, Biggs y Purdie, 1996; Yu y Chiu, 2019).

A continuación, se explicará la metodología y los resultados obtenidos con el modelo pedagógico implementado para finalmente cerrar con las conclusiones y discusión de esta experiencia.

\section{METODOLOGÍA}

\subsection{DESCRIPCIÓN DEL CONTEXTO}

Esta experiencia se desarrolló el año 2015 en un aula multigrado de educación parvularia de una escuela rural ubicada en la zona costera de la comuna de Valdivia, Región de Los Ríos, Chile. Involucró a la educadora de párvulos y a la amiga crítica que acompañó el proceso.

El curso estaba compuesto por doce niños entre 4 y 5 años. En su mayoría, provenían de familias de escasos recursos ${ }^{3}$ ya que los ingresos familiares, en el $80 \%$ de los casos, provenían de trabajos esporádicos de recolección de productos del mar, atención turística en temporada estival, y otros trabajos u oficios temporales en la agricultura o ganadería. Por otra parte, en el $50 \%$ de los casos la jefatura del hogar era asumida por la madre.

\subsection{OBJETIVO}

El objetivo de este artículo es documentar el desarrollo y los logros obtenidos por una educadora de párvulos que se comprometió con una práctica reflexiva-colaborativa, para enriquecer el proceso de enseñanza-aprendizaje, mediado por una amiga crítica a lo largo de la aplicación de un proyecto pedagógico llamado Contarte.

\subsection{ESTRATEGIA DE EXPLORACIÓN}

Para analizar este proyecto pedagógico-didáctico, se eligió la sistematización de experiencias (SE). Esta permite hacer observación y seguimiento de la realidad educativa,

Información obtenida de la ficha de matrícula. 
para comprender el aprendizaje y la intervención "desde" y "para" la práctica (Guiso, 2001). La SE educativa se fundamenta en el paradigma cualitativo y tiene como meta la exploración de contextos para obtener descripciones y explicar la realidad subjetiva de las prácticas de una manera socio-crítica (Ghiso, 1998; Restrepo y Tabares, 2000).

\subsection{REGISTRO DE LA EXPERIENCIA}

Un importante elemento de la SE educativa es la documentación. Esta constituye una evidencia o una forma de registrar lo vivido. Algunos ejemplos son el diario, las memorias de colectivos, las reuniones del grupo base y los conversatorios con estudiantes (BarbosaChacón, Barbosa y Rodríguez, 2015).

Para documentar esta SE, se utilizaron diversas formas de registro:

- Diario de campo y bitácora de clases para registrar los acontecimientos relevantes de la práctica que permitieran identificar incidentes críticos que posibilitaran profundizar en la reflexión.

- Documentación pedagógica como planificaciones, registros audiovisuales (imágenes, fotografías y videos) y trabajos de los niños para argumentar, narrar y explicar procesos, situaciones y experiencias.

- E-mail y WhatsApp para comunicarse con la amiga crítica, compartiendo lo sucedido en las clases focalizadas en esta investigación.

\subsection{ANÁLISIS}

El análisis de la información se desarrolló en base a "momentos" (Redondo y Navarro, 2007): de análisis individual y de análisis grupal (ver Tabla 1).

Tabla 1. Momentos de la estrategia

\begin{tabular}{|l|l|}
\hline Momento de análisis individual & $\begin{array}{l}\text { Reporte individual de la experiencia: identificación de categorías } \\
\text { basada en los registros del diario de campo (utilizando elementos } \\
\text { de la planificación del aprendizaje y extrayendo categorías } \\
\text { emergentes). }\end{array}$ \\
\hline Momento de análisis grupal & $\begin{array}{l}\text { i) Discusión colaborativa sobre las categorías identificadas, } \\
\text { ii) Generación de grandes categorías para analizar el corpus } \\
\text { textual de la experiencia completa, y } \\
\text { iii) Análisis cualitativo de todos los registros. }\end{array}$ \\
\hline
\end{tabular}

Fuente. Tomado de Barbosa-Chacón, Barbosa y Rodríguez (2015). 


\subsection{DESCRIPCIÓN DE LA EXPERIENCIA}

Metodológicamente, el compromiso de reflexión se asumió a través de una serie de procesos que se re-alimentaron unos a otros de forma circular y continua (ver figura 1).

Figura 1. La experiencia de práctica reflexiva con amiga crítica de Contarte.

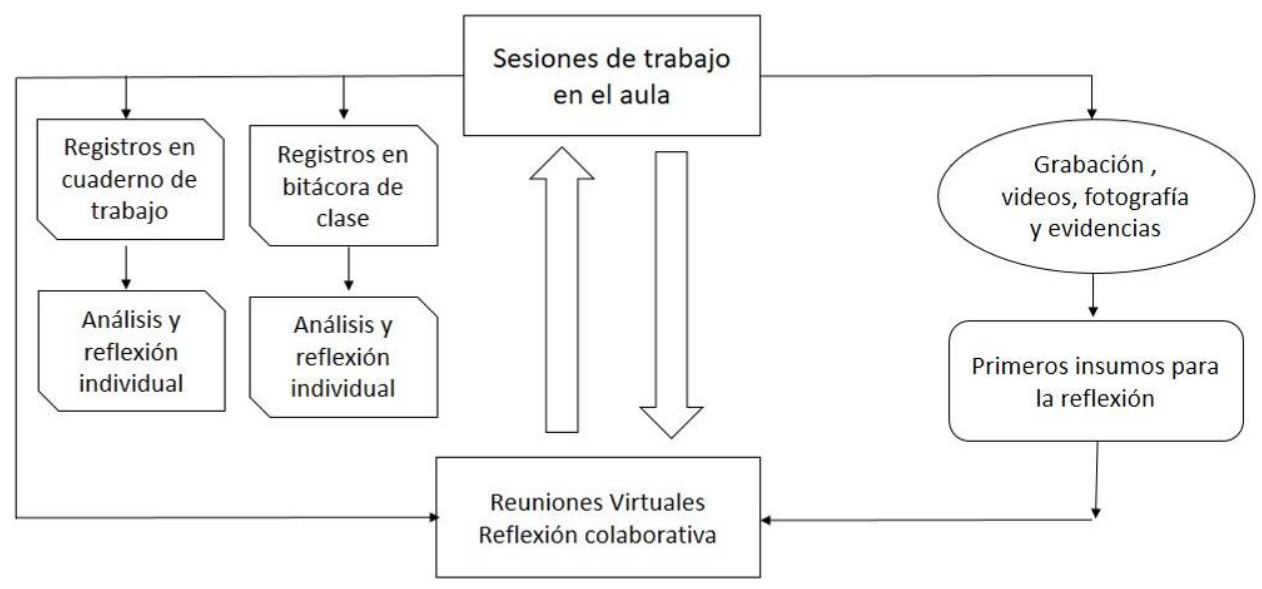

Fuente. Elaboración propia.

\subsubsection{Diagnóstico e indagación del problema}

Al finalizar el año escolar 2014, y tras analizar el período, la educadora llegó a la conclusión de que los niños lograban expresar oralmente sus necesidades, manejaban un lenguaje oral acorde a su contexto y se desenvolvían adecuadamente en lo cotidiano; pero presentaban dificultades para comprender los textos trabajados en el aula, fueran estos orales o escritos; tomar la palabra y participar; incorporar palabras nuevas en sus producciones orales y relacionar textos con sus experiencias.

Frente a esta problemática, sumado a la incorporación de un grupo nuevo de niños a su clase, decidió embarcarse en un proyecto de innovación que permitiera poner en juego nuevas estrategias didácticas que promovieran las competencias comunicativas de sus alumnos.

\subsubsection{Diseño del proyecto Contarte}

Para implementar Contarte, la educadora decidió utilizar la estrategia de lectura compartida (Goikoetxea y Martínez, 2015), dado el componente conversacional que esta involucra (Swartz, 2010). Priorizó el trabajo con textos poéticos por considerar que la interacción que estos propician entre texto y lector permiten a los niños ensayar libremente y en un contexto protegido, sus sentimientos, emociones e ideas, pilares fundamentales de su expresión oral, capacidad interpretativa y desarrollo de la creatividad (Coles, 2017). 
La secuencia didáctica consideró cinco sesiones para abordar cada texto, dedicando alrededor de una quincena a cada tema. Cada sesión se estructuró en diversos momentos para propiciar el desarrollo de competencias comunicativas en los niños: lectura compartida, preguntas, representación visual, socialización de trabajos, diálogo colectivo y juegos (Arnold y Fonseca, 2003; Herrada-Valverde y Herrada, 2017). Se realizaron tres ciclos de implementación, compuestos cada uno por cuatro textos poéticos.

\section{RESULTADOS}

Estos resultados surgen de la SE de la reflexión colaborativa realizada por la díada educadora-amiga crítica, en cada ciclo de implementación. La experiencia se representa en tablas indicando el texto poético trabajado, la sesión, la descripción de la situación pedagógica y la respuesta de los niños. Posteriormente se presentará la reflexión pedagógica de la educadora y la síntesis de la reflexión diádica.

\subsection{PRIMER CICLO DE IMPLEMENTACIÓN}

Este ciclo se desarrolló durante 6 semanas a partir de la primera quincena de abril de 2015 . Los textos poéticos se seleccionaron en función de los criterios que la educadora consideró pertinentes (valor estético de la obra, musicalidad, desafío cognitivo y contenido). Estos textos fueron: Todo es Ronda de Gabriela Mistral, El Barquito de Papel de Amado Nervo, Paisaje de Nicanor Parra y La Vaca Estudiosa de María Elena Walsh (ver Tabla 2). 
Tabla 2. Primer ciclo de implementación

\begin{tabular}{|c|c|c|c|}
\hline Texto poético & Sesión & $\begin{array}{c}\text { Descripción de la situación } \\
\text { pedagógica }\end{array}$ & Ejemplo de respuesta de los niños \\
\hline $\begin{array}{l}\text { El Barquito de } \\
\text { Papel } \\
\text { Amado Nervo }\end{array}$ & 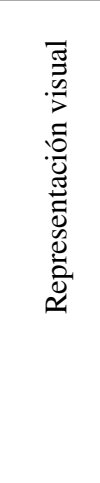 & $\begin{array}{l}\text { La educadora pide a los niños } \\
\text { que interpreten su dibujo. } \\
\text { "¿Dónde viajaste en tu barquito } \\
\text { de papel? ¿Con quién fuiste?" }\end{array}$ & $\begin{array}{l}\text { "Yo fui a China en mi barco y había } \\
\text { muchas cosas lindas, fui a ver fuegos } \\
\text { artificiales y volví a Niebla y aquí } \\
\text { había puras frutas porque yo tenía } \\
\text { hambre" (Jacinta, } 4 \text { años, bitácora de } \\
\text { la clase, } 24 \text { de abril) }\end{array}$ \\
\hline $\begin{array}{l}\text { Paisaje } \\
\text { Nicanor Parra }\end{array}$ & 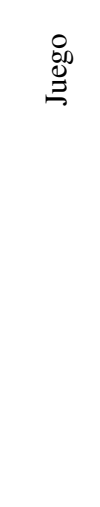 & $\begin{array}{l}\text { Luego de leer la poesía, en la } \\
\text { sesión de juego la educadora, } \\
\text { mientras los niños están bajo la } \\
\text { mesa, pregunta: "¿En qué lugar } \\
\text { estás? ¿Quién está contigo? } \\
\text { ¿Cómo te sientes ahí y por qué?" }\end{array}$ & $\begin{array}{l}\text { "Estamos acampando. Es un lugar } \\
\text { muy bonito. No tengo miedo y estoy } \\
\text { con mi hermano dentro de una carpa" } \\
\text { (Cristián, } 5 \text { años, bitácora de la clase, } \\
07 \text { de mayo). }\end{array}$ \\
\hline $\begin{array}{l}\text { La Vaca } \\
\text { Estudiosa } \\
\text { María Elena } \\
\text { Walsh. }\end{array}$ & 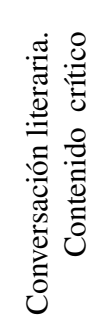 & $\begin{array}{l}\text { Durante la conversación literaria } \\
\text { la educadora preguntó: “¿Qué } \\
\text { haríamos si en este momento } \\
\text { una vaca quisiera entrar a la sala } \\
\text { a estudiar con nosotros?" }\end{array}$ & $\begin{array}{l}\text { "iLa comemos!" (Jacinta, } 4 \text { años. } \\
\text { Bitácora de la clase, } 19 \text { de mayo) }\end{array}$ \\
\hline
\end{tabular}

Fuente. Elaboración propia.

Esta fase no incluía inicialmente la representación artística, pero a medida que el trabajo con el primer texto poético fue avanzando, la educadora decidió propiciar tanto representaciones lúdicas como visuales.

Esta decisión se fortaleció al tomar conciencia de que los niños, al describir sus obras, compartían no solo el contenido literal del texto, sino que ellos, además, expresaban su necesidad de contar sus sueños, sentimientos y experiencias (ver Tabla 2). 
Al leer las respuestas que dieron cuando me contaron hacia dónde viajaron y con quién, me di cuenta de que tenían la necesidad de representar imágenes propias que les permitieran comunicar su propio mundo. Ellos no se quedaron en lo literal, fueron mucho más allá (Educadora, Diario de campo, semana 3 de abril).

A través del diálogo con la amiga crítica la educadora tomó conciencia de que aquellas situaciones que propiciaron interacciones de juego y representación visual gatillaron la intención comunicativa de los niños. Lo que le mostró que son ellos, quienes, a partir de sus propuestas, tomaron espacios para expresarse de manera más libre y espontánea.

Sus respuestas son espontáneas, y la necesidad de comunicar sus emociones o pensamientos demuestran la importancia de su protagonismo en la producción oral cuando las condiciones son favorables, como es en el caso de un juego (Educadora, Diario de campo, semana 1 de mayo).

A partir de la revisión de las notas del diario y los registros en la bitácora de la clase, se discutió con la amiga crítica en torno a la complejidad y propósito de las preguntas que la educadora formuló durante las sesiones de trabajo,

Quise conducir la conversación hacia contenidos relacionados con la integración, sin embargo, ellos la conectaron con su experiencia rural y campesina y no supe cómo seguir e intentaba forzarlos a responder a mi pregunta (Educadora, Diario de campo, semana 3 de mayo).

Al socializar este episodio con la amiga crítica tensionó el protagonismo que la educadora asumía durante el desarrollo de las experiencias

Creo que un aspecto clave es el concepto de que la comprensión está vinculada al descubrimiento del texto [...] el interés que produce en el mediador para transmitirlo... lo que va más allá de la mecanización de un método o programa (Amiga crítica, WhatsApp, semana 2 de mayo).

Hasta aquí, los procesos reflexivos observados en la educadora se corresponden con un nivel de reflexión superficial, fundamentalmente porque sus creencias y posturas sobre sus prácticas de enseñanza se basan en la experiencia práctica.

A partir del análisis del primer ciclo de la intervención, basado en la recuperación de la experiencia en la práctica, educadora y amiga crítica identificaron algunos aspectos de la práctica que debían ser cautelados: i) el tipo y contenido de los textos poéticos que se les ofrecían a los niños, ii) la preparación previa de las preguntas a realizar durante las lecturas, juegos y procesos de representación visual, asegurando la generación de espacios de expresión más libres, iii) el tipo de interacción que se promueve, poniendo especial cuidado en practicar el juego guiado, es decir, iniciar el juego y dejar que sean los niños quienes lo continúen. 


\subsection{SEGUNDO CICLO DE IMPLEMENTACIÓN}

A partir de los resultados obtenidos en el ciclo anterior, la educadora decide acercar a los niños a la poesía hispanoamericana, principalmente para desafiarlos con textos que requerían mayores capacidades interpretativas con contenidos inferenciales de mayor complejidad y para iniciarlos en la exploración de figuras literarias como las metáforas. Los textos elegidos para este segundo ciclo de intervención fueron: El Lagarto está Llorando de Federico García Lorca, Por el Ojo de la Aguja de Andrés Sabella, Pegasos, Lindos Pegasos de Antonio Machado, y En Mapudungun de María Lara Millapán (ver tabla 3).

En una modalidad abierta y flexible se inició la implementación del segundo ciclo. Aplicando los conocimientos recién adquiridos, la educadora analizó el contenido del texto y decidió iniciar con El Lagarto está Llorando por poseer un lenguaje simple y ser una temática cercana a la experiencia de los niños: "la pérdida de objetos que son valiosos para ellos y la emoción que esa pérdida provoca", permitiendo que fueran ellos quienes guiaran la experiencia al iniciar las lecturas.

Tabla 3. Segundo ciclo de implementación

\begin{tabular}{|c|c|c|c|}
\hline Texto poético & Sesión & $\begin{array}{c}\text { Descripción de la situación } \\
\text { pedagógica }\end{array}$ & Respuesta de los niños \\
\hline $\begin{array}{l}\text { El Lagarto } \\
\text { EstáLlorando } \\
\text { Federico } \\
\text { García Lorca }\end{array}$ & 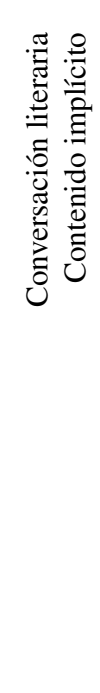 & $\begin{array}{l}\text { Luego de la lectura la educadora pre- } \\
\text { gunta: } \\
\text { “Por qué lloran los lagartos?” } \\
\text { "Porque perdieron los anillos de casa- } \\
\text { dos”, responde Cristian. } \\
\text { Juan pregunta a la educadora: } \\
\text { “Por qué lloran por eso?” } \\
\text { Ante la pregunta de Juan, la educado- } \\
\text { ra contra-pregunta: } \\
\text { “Por qué creen ustedes que eso les da } \\
\text { tanta pena?” }\end{array}$ & $\begin{array}{l}\text { "Yo creo que es porque se casa- } \\
\text { ron y usan un anillo, y están } \\
\text { enamorados" (Jacinta, } 4 \text { años). } \\
\text { Juan interpeló a su compañera } \\
\text { diciendo: "No sé por qué lloran } \\
\text { cuando se le pierden los anillos. } \\
\text { Mis papás no se casaron, no } \\
\text { usan anillo y se siguen aman- } \\
\text { do". } \\
\text { "No deberían llorar, pueden tra- } \\
\text { bajar y comprarse otro" (Jacin- } \\
\text { ta, } 4 \text { años). } \\
\text { "Sólo si quieren pueden com- } \\
\text { prarlo, pueden vivir juntos y te- } \\
\text { ner hijos" (Victoria, } 5 \text { años). } \\
\text { - "Sí, pueden hacer una familia } \\
\text { igual" (Claudio, } 4 \text { años, bitáco- } \\
\text { ra de la Clase, } 02 \text { de junio). }\end{array}$ \\
\hline
\end{tabular}




\begin{tabular}{|c|c|c|c|}
\hline $\begin{array}{l}\text { Pegasos, } \\
\text { Lindos } \\
\text { Pegasos } \\
\text { Antonio } \\
\text { Machado }\end{array}$ & 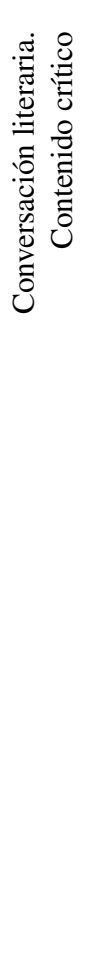 & $\begin{array}{l}\text { Durante la sesión de conversación li- } \\
\text { teraria, la educadora pregunta: } \\
\text { "Si en este momento cayera un pegaso } \\
\text { aquí ¿qué haríamos con él?" }\end{array}$ & $\begin{array}{l}\text { "Le curaría su ala porque debe } \\
\text { estar mala" (Jimena, } 5 \text { años). } \\
\text { - "Sí, me lo llevo a mi casa y lo } \\
\text { cuido para volar con él hasta el } \\
\text { cielo" (Jimena, } 5 \text { años) } \\
\text { "Si tú te llevas el pegaso a tu } \\
\text { casa, él no será feliz, porque no } \\
\text { estará con su mamá" (Andrea, } 5 \\
\text { años). } \\
\text { "Pero si yo me quedo con él } \\
\text { puedo viajar al cielo para ver a } \\
\text { mi papá que está allá" (Jimena, } \\
5 \text { años). } \\
\text { "Entonces lo ocupas un ratito y } \\
\text { se lo devuelves a su mamá, por- } \\
\text { que si no ella también estará } \\
\text { muy triste" (Andrea, } 5 \text { años, Bi- } \\
\text { tácora de la clase, } 30 \text { de junio). }\end{array}$ \\
\hline $\begin{array}{l}\text { En } \\
\text { Mapuzungun } \\
\text { María Lara } \\
\text { Millapán }\end{array}$ & 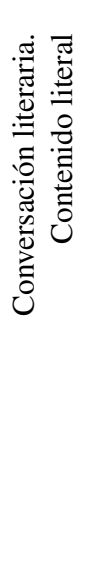 & $\begin{array}{l}\text { En el contexto de la lectura del texto } \\
\text { por parte del educador tradicional, la } \\
\text { educadora nombra a los niños que tie- } \\
\text { nen apellidos mapuche y, por lo tanto, } \\
\text { ella señala "son mapuches". }\end{array}$ & $\begin{array}{l}\text { Julián pregunta: } \\
\text { - ¿Y tú eres mapuche? } \\
\text { - No, yo no soy mapuche por- } \\
\text { que no tengo apellido mapuche. } \\
\text { - Estás equivocada, porque tor } \\
\text { dos somos mapuches, porque } \\
\text { mapuche significa "gente de la } \\
\text { tierra" (Julián, } 5 \text { años, bitácora } \\
\text { de la clase, } 12 \text { de agosto). }\end{array}$ \\
\hline
\end{tabular}

Fuente. Elaboración propia. 
Tras finalizar el segundo ciclo de implementación, la intervención de la amiga crítica permitió que la educadora pudiera reflexionar sobre la formulación de preguntas y su incidencia en los resultados observados. Las experiencias educativas desarrolladas durante este ciclo de implementación la sorprendieron, pues logró realizar registros de las intervenciones de los niños en los diálogos, observando cómo lograron establecer redes de comunicación entre ellos a partir de las preguntas que ella les formuló durante las sesiones, principalmente en la conversación literaria. La educadora logró hacerse consciente de cómo los niños encontraron un espacio de confianza donde expresaron no tan sólo sus experiencias, sino también sus opiniones y puntos de vista.

Ellos se apropiaron del espacio e interpelaron al texto, a mí y por primera vez se interpelaron entre sí. Al darme cuenta de lo que estaba sucediendo generé, en esta oportunidad, preguntas críticas y a su vez contra-preguntas que les invitaron a responder desde su análisis textual y desde su propia experiencia. A nivel comprensivo dieron cuenta de la relación entre la lectura y sus experiencias de vida, las que utilizaron para interpretar e interpelar la lectura (Educadora, Diario de campo, semana 1 de junio).

Al discutir sobre los procesos dialógicos que se fueron dando durante este ciclo de implementación, ella registró,

Introduje una pregunta abierta que buscó propiciar la imaginación en una situación fantástica. Los niños tomaron la pregunta y abrieron un debate generando respuestas ligadas a la fantasía, en algunos casos y otros ligados a su experiencia de vida. El contenido del texto, la conversación literaria y la pregunta abrieron espacios de discusión de mayor profundidad (Educadora, Diario de campo, semana 4 de junio).

La amiga crítica retroalimentó la práctica, a partir de los videos compartidos digitalmente, señalando:

Es el tipo de preguntas lo que incide en el análisis textual. Las preguntas que estás formulando han ido creciendo en nivel de complejidad. Además de que, para los niños el espacio de conversación ya es una práctica instalada. Ahora comienzan a formular preguntas, a requerir mayor información del propio texto y a vincular con su experiencia de vida. El análisis crítico comienza a emerger y las preguntas que tú formules deben ser cada vez más desafiantes (Registro de diálogo, WhatsApp, junio 2015).

Ambas concluyeron que las preguntas permitieron a los niños iniciar conversaciones literarias más complejas y nuevamente se suscitaron diálogos entre ellos a partir de la reflexión del texto.

El objetivar, reconocer, reconstruir e interpretar críticamente la experiencia permitió que la docente comprendiera cómo sus prácticas de enseñanza incidían en el aprendizaje de los niños y qué es lo que debe considerar para mejorar las experiencias de aprendizaje para todos ellos. El ser consciente de que una nueva forma de análisis literario se instaló entre los niños y de que además discutieron, argumentaron y contraargumentaron, le permitió asociar hechos en un marco más amplio, lo que es propio de un nivel de reflexión pedagógica. 
Sin embargo, este avance no se mantiene estable en el tiempo, lo que se evidencia al terminar el ciclo a partir de un quiebre con el poema En Mapuzungun, que llevó a la educadora a hacerse consciente de que estaba subvalorando las capacidades de los niños.

Me sentí reduccionista, prejuiciosa, ignorante de la forma en que ellos ven y comprenden el mundo. Sentí pudor y vergüenza frente a mi ignorancia (Educadora, Diario de campo, semana 2 de agosto).

Este episodio no fue socializado inmediatamente con la amiga crítica. Pasaron algunos días entre ocurrido este y la puesta en común a través del WhatsApp.

En la medida que los adultos les demos la oportunidad a los niños para ejercitar la autonomía, como está ocurriendo en tu aula, si tomamos en cuenta su creciente habilidad para participar y tomar decisiones les estamos abriendo un espacio social del cual se apropian y se sienten parte. Esto trae como consecuencia que ellos se sienten en la libertad de cuestionar las ideas de los adultos. Lo anterior nos desafía, debemos superar la tendencia innata y heredada de ejercer nuestra autoridad sobre ellos (Registro de diálogo, WhatsApp, agosto 2015).

Tras esta constatación decidió introducir poemas que fueran más complejos. Textos que complementados con imágenes vinculadas con la realidad sociocultural de los niños permitieran, por un lado, que el adulto asumiera un rol de guía y orientación en el aprendizaje y por otro que los niños practicaran a través de la conversación, el juego y la representación visual, la autonomía y desarrollaran el pensamiento crítico.

\subsection{TERCER CICLO DE IMPLEMENTACIÓN}

Para iniciar el tercer ciclo de intervención, la educadora decidió enfrentar a los niños a textos del folklore poético basándose en el criterio de que estos estaban vinculados con el contexto próximo de sus participantes. Por tratarse de temáticas asociadas a sus intereses, a figuras infantiles y a problemáticas asociadas a sus sentimientos y emociones, la educadora eligió: Luchín de Víctor Jara, El Volantín de Ángel Parra, La Tristeza Traviesa de Liliana Cristina Cinetto y El Rin del Angelito de Violeta Parra (ver Tabla 4).

Las imágenes que acompañaron los textos se diseñaron abordando elementos asociados a su entorno próximo, con características físicas de la zona a la cual pertenecen y con elementos pertinentes propios del ambiente natural, flora y fauna local. 
Tabla 4. Registros tercer ciclo de intervención

\begin{tabular}{|c|c|c|c|}
\hline $\begin{array}{l}\text { Texto } \\
\text { poético }\end{array}$ & Sesión & $\begin{array}{l}\text { Descripción de la situación } \\
\text { pedagógica }\end{array}$ & Respuesta de los niños \\
\hline $\begin{array}{l}\text { Luchín } \\
\text { Víctor Jara }\end{array}$ & 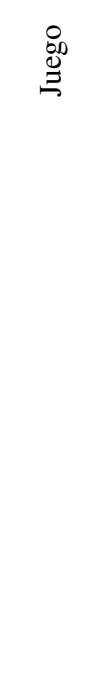 & $\begin{array}{l}\text { Luego de la lectura y la recupe- } \\
\text { ración de contenidos de la se- } \\
\text { sión anterior, los niños realiza- } \\
\text { ron una lista de los juegos de } \\
\text { Luchín y los juegos de ellos. Al } \\
\text { concluir, la educadora pregun- } \\
\text { ta: "¿Qué piensan de esta lista } \\
\text { que hicimos?" }\end{array}$ & $\begin{array}{l}\text { "Que Luchín tiene más suerte que noso- } \\
\text { tros, él se ensucia y su mamá no lo reta } \\
\text { como a nosotros" (Armando, } 5 \text { años). } \\
\text { "No importa, cuando jugamos en el ba- } \\
\text { rro es entretenido, no importa que te re- } \\
\text { ten, Luchín también juega como noso- } \\
\text { tros" (Jacqueline, } 5 \text { años, bitácora de la } \\
\text { clase, } 27 \text { de agosto). }\end{array}$ \\
\hline $\begin{array}{l}\text { La Tristeza } \\
\text { Traviesa } \\
\text { Liliana } \\
\text { Cristina } \\
\text { Cinetto }\end{array}$ & 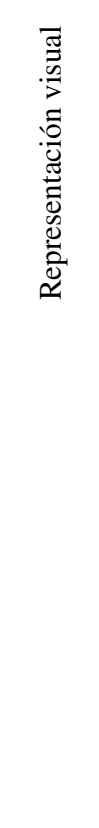 & $\begin{array}{l}\text { Luego de leer la lectura y reali- } \\
\text { zar la sesión de conversación } \\
\text { literaria, se realiza un proceso } \\
\text { de planificación de la represen- } \\
\text { tación visual ligada a la expre- } \\
\text { sión según el análisis literario. } \\
\text { En la fase de ejecución de la } \\
\text { obra visual, cuando dan forma } \\
\text { a su obra plástica, se pregunta a } \\
\text { niños y niñas durante el proce- } \\
\text { so de monitoreo: } \\
\text { ¿Cuál es tu tristeza traviesa? } \\
\text { ¿Por qué está ahí esa tristeza? } \\
\text { ¿Qué sucedió que hay una } \\
\text { mancha oscura? ¿Por qué } \\
\text { dibujaste una línea en el } \\
\text { medio?" }\end{array}$ & $\begin{array}{l}\text { "Mi tristeza traviesa es esta mancha que } \\
\text { está ahí... es oscura... es negra... está } \\
\text { en mi pecho." } \\
\text { "Eso es cuando mi mamá y mi papá pe- } \\
\text { lean, a mí no me gusta eso, me pongo } \\
\text { triste" } \\
\text { "Porque en este lado de la hoja voy a } \\
\text { pintar cuando ellos pelean y yo me pon- } \\
\text { go triste, a este otro lado voy a dibujar } \\
\text { cuando ellos se quieren y se aman y así } \\
\text { todos estamos contentos." (Cristian, } 5 \\
\text { años, bitácora de la clase } 23 \text { de octubre). }\end{array}$ \\
\hline
\end{tabular}




\begin{tabular}{|c|c|c|c|}
\hline $\begin{array}{l}\text { El Rin del } \\
\text { Angelito } \\
\text { Violeta } \\
\text { Parra }\end{array}$ & 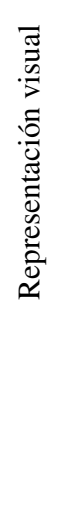 & $\begin{array}{l}\text { Durante la sesión de represen- } \\
\text { tación visual, en el momento } \\
\text { de explicar lo que se había re- } \\
\text { presentado, la educadora pre- } \\
\text { guntó "¿y esa es una nube?" } \\
\text { Quien luego de escuchar vuel- } \\
\text { ve a preguntar "¿y cómo te } \\
\text { sientes tú cuando te quedas } \\
\text { abajo?" }\end{array}$ & $\begin{array}{l}\text { "Esta es el alma de mi papi. Se va al cie- } \\
\text { lo, arriba. Se va a ver al alma de mis ta- } \\
\text { tas que murieron... abajo queda mi } \\
\text { mami y yo". "No me da pena. Me quedo } \\
\text { contenta porque mi papi está triste sin } \\
\text { su mami y su papi" (Sofía, } 4 \text { años, Bitá- } \\
\text { cora de la clase, } 20 \text { de noviembre 2015). }\end{array}$ \\
\hline
\end{tabular}

Fuente. Elaboración propia.

Las preguntas de la educadora fueron abordando contenidos cada vez más complejos, permitiendo que los niños construyeran una experiencia globalizadora de cada unidad poética. Los niños, a partir de la conversación iniciada por la educadora y guiada por ellos, comenzaron a comprender que las imágenes podían ayudarles a comunicar algo, esto se evidenció durante el proceso de elaboración de sus trabajos y durante las exposiciones finales.

Vi cómo los niños comenzaron a relacionar la idea de que sus imágenes podían ayudarles a comunicar sentimientos. Mientras pintaban, contaban los significados que atribuían a sus propias imágenes y cómo estas se conectaban con el contenido del texto (Educadora, Diario de campo, semana 4 de octubre).

Las actuaciones de los niños fueron objeto de reflexión, la docente pensaba constantemente en cómo sus prácticas afectaban su aprendizaje y en cómo mejorar las experiencias de aprendizaje para todos ellos. Durante este proceso conceptos como el adultocentrismo, el diálogo como centro del aprendizaje, el juego y la expresión visual fueron adquiriendo sentido en la práctica, lo que le permitió ver la multidimensionalidad del proceso enseñanza-aprendizaje, ayudándola a asociar hechos en un marco más amplio. Nuevamente, esto demuestra un nivel de reflexión pedagógica.

Aun cuando el texto no decía que Luchín era un niño, para ellos se hizo explícito que el protagonista era un niño. Por la cercanía etaria, ellos establecieron una relación de empatía, imaginando a Luchín como uno igual a ellos (Educadora, Diario de campo, semana 4 de agosto).

Los videos de las descripciones que realizaron los niños de sus obras fueron compartidos con la amiga crítica, quien cuestionó los logros y tensionó la práctica de la educadora.

¿A qué atribuyes estos avances? ¿Por qué piensas que los niños y las niñas han logrado dar estos significados a sus obras? (Amiga crítica, WhatsApp, octubre). 
Yo creo que abrí mi mente y flexibilicé mis propias actuaciones. Ahora, cuando planifico, pienso en qué puede ser significativo para ellos, cómo lo abordo y les permito expresarse libremente. No espero un contenido, sino que espero poder observar cómo manifiestan sus ideas, sentimientos y pensamientos sobre algo que les resulta interesante (Educadora, WhatsApp, octubre).

Lo anterior se pudo observar en la lectura crítica que los niños hicieron durante la conversación literaria. El ser sensible, saber escuchar y dar el tiempo a cada uno para elaborar sus ideas y expresarlas, fue uno de los aspectos que, desde la reflexión sobre la acción, permitieron a la educadora reformular sus propias experiencias, lo que constituye el referencial que le da sentido a su práctica.

Escuchar la respuesta de Sofía me hizo repensar la forma en que tengo que interactuar con los niños, no puedo asumir algo, debo estar dispuesta a escuchar lo que ellos me tienen que decir y validarlo como parte de sus experiencias (Educadora, Diario de campo, semana del 20 de noviembre 2015).

Estos resultados muestran que el alcance reflexivo en torno a la práctica docente fue un factor determinante en relación a la capacidad de la educadora para generar instancias para el desarrollo de las competencias comunicativas de los niños, a través de diferentes actividades y preguntas.

A partir del análisis, la síntesis y valoración de las acciones realizadas, la docente con la ayuda de la amiga crítica se dio cuenta de que iniciando procesos que vincularan interrogación y relación texto, experiencia e imagen, podía promover en los niños construcciones cada vez más complejas de su propia realidad.

$\mathrm{Al}$ analizar las decisiones tomadas por la educadora, la díada coincidió en señalar que buscaba "ser y hacer mejor", por lo tanto, que dinamizaba dialécticamente la relación entre el conocimiento teórico que ya tenía con los conocimientos que surgieron de las nuevas e inéditas situaciones.

\section{DISCUSIÓN Y CONCLUSIONES}

Esta experiencia permitió documentar los procesos reflexivos vinculados con el ejercicio pedagógico desarrollado por una docente en acompañía una amiga crítica. La SE Contarte llevó a la identificación de las prácticas que democratizaron las oportunidades de desarrollo de competencias comunicativas en los niños y niñas con el objeto de reconocerlas y reconstruirlas (Nelson, Welsh, Vance y Greenberg, 2011; Snow, Tabors y Dickinson, 2001; Whitehurst y Fischel, 2000).

Más que escribir, recopilar u ordenar información (Jara, 1998; Vasco, 2008; Sánchez, 2010), Contarte fue un compromiso por "observar" y "hacer seguimiento" de la práctica docente que se materializó en la recuperación, análisis y apropiación de las prácticas educativas (Barbosa, 2010) a través de la sistematización de la actividad reflexiva.

Los resultados de esta SE muestran que la relación entre investigadora y amiga crítica propició que ambas se expusieran a la crítica de la otra, reflexionaran colaborativamente y formularan constantemente preguntas para lograr una mayor claridad en lo abordado 
(Petroelje et al., 2018). La necesidad de construir confianza entre los implicados (Baskerville y Goldblatt, 2009; Swars et al., 2018) y la importancia del cómo retroalimentar cuando se cumple el rol de amigo crítico (Kiewkor, Wongwanich y Piromsombat, 2014) son temas que la bibliografía aborda revelando la complejidad de lograr un balance entre el apoyar y desafiar la práctica del otro (Swaffield, 2007; Watling, Hopkins, Harris y Beresford, 1998).

A pesar de sus complejidades, en este estudio la práctica reflexiva docente-amiga crítica avanzó, sin alcanzar un nivel de reflexión crítica, de un plano superficial a uno pedagógico (Larrive, 2008). Coincidente con autores que refieren a cómo los amigos críticos se mueven entre las fases de un continuum avanzando en función de la construcción de confianza, sentido de comunidad y fluidez en el trabajo (Baskerville y Goldblatt, 2009; Swars et al., 2018), fue posible observar un ir y venir entre los mencionados niveles de reflexión; sin descartar el futuro logro de mayor especificidad y profundidad con el pasar de más sesiones reflexivas en conjunto (Fen et al., 2017).

Adicionalmente, los hallazgos muestran el poder emancipador del desarrollo profesional docente en torno a la práctica reflexiva conjunta (Giroux, 1997); en un proceso donde la docente se vuelve consciente de su propia práctica pedagógica a través de los ojos de una colega (Wennergren, 2016). A través del análisis de "las habilidades de los observadores para describir, interpretar, evaluar y predecir a partir de lo que observan" (Muller, Volante, Grau y Preiss, 2014, p. 4), este estudio releva el papel de la retroalimentación en tanto que comparte, analiza y comprende (Leiva, Montecinos y Aravena, 2017). En ese sentido, la retroalimentación, en tanto que oportunidad de trabajar colaborativamente, indagando en problemas de aula y construcción de relaciones fuertes entre profesores; condujo a un mayor compromiso por parte de las docentes que participaron de esta investigación haciéndolas sentir mejor preparadas para continuar comprometiéndose con la labor pedagógica (Aktekin, 2019).

En consideración de que los niños participantes de este estudio provenían de un contexto desfavorecido, los resultados de esta sistematización son, por una parte, esperanzadores; abriendo paso a la posibilidad de que el desarrollo profesional docente, particularmente en relación a la reflexión colaborativa entre docente-amiga crítica, sea una herramienta para la justicia social para aquellos niños que cuentan con menos desafíos lingüísticos, menos interacciones comunicativas con adultos, menos sensibilidad por parte de estos a los "temas de niños", así como también menos estrategias de andamiaje que faciliten la atención, el procesamiento y el aprendizaje por parte de las educadoras (Evans, 2004; Landry, Smith, Swank, Assel y Vellet, 2001; Weizman y Snow, 2001).

Lo anterior permite afirmar que la apropiada intervención de un par más experto puede ser de gran utilidad para el docente y para el amigo crítico, en lo que Zeichner (1993) describiría como el proceso de examinar, cuestionar y perfeccionar las prácticas educativas con la finalidad de minimizar las situaciones de desigualdad e injusticias que se dan en las aulas; o, a lo que análogamente Freire (1999) se refiere como un avanzar con responsabilidad social y política hacia la profundización de los diversos problemas educativos; problemas tales como el escaso desarrollo de competencias comunicativas en contextos desaventajados.

Estos resultados muestran que a partir de la búsqueda de descripciones y explicaciones de la realidad subjetiva desde un abordaje socio-crítico (Restrepo y Tabares, 2000) como parte fundamental de las sesiones reflexivas y gracias a la existencia de un par más experto, se llegó a relacionar sistémica e históricamente los elementos teóricos, prácticos 
y contextuales de la sistematización de Contarte. Lo hallado invita a explorar junto a otros actores del proceso educativo lo que ocurre en el aula, sometiendo la experiencia a procesos de objetivación, observación y dinamización; con la rigurosidad que demanda el conocer el impacto que tiene en los estudiantes y por ende, en la sociedad, las decisiones que toman los docentes.

\section{REFERENCIAS BIBLIOGRÁFICAS}

Abou, M. (2007). Levels of Reflection in Action Research. An Overview and an Assessment Tool. Teaching and Teacher Education, 23(1), 24-35. https://doi.org/10.1016/j.tate.2006.04.002 Agencia de Calidad de la Educación (2019a). Resultados educativos 2018. Recuperado de http:// archivos.agenciaeducacion.cl/Conferencia_EERR_2018.pdf

(2019b). Resultados educativos 2018. Región de Los Ríos. Recuperado de: http://archivos. agenciaeducacion.cl/LOS_RIOS.pdf

Aktekin, N. (2019). Critical Friends Group (CFG): Inquiry-Based Professional Development Model for Turkish EFL Teachers. Eurasian Journal of Educational Research, 81, 1-20. https://doi. org/10.14689/ejer.2019.81.1

Arnold, J. y Fonseca, M. C. (2003). Reflexiones sobre aspectos del desarrollo de la competencia comunicativa oral en el aula de español como segunda lengua. Disponible en https://cvc. cervantes.es/ensenanza/biblioteca_ele/antologia_didactica/claves/arnold_fonseca.htm

Arredondo, D., Beas, J., Gómez, V., Thomsen, P. y Carranza, G. (2009). Conceptual Change among Teachers Involved in Educational Reform. International Journal of Leadership in Education: Theory and Practice, 12(2), 155-169. https://doi.org/10.1080/13603120802549790

Barbosa, J. (2010). El guión de aprendizaje como eje para la virtualización. Veracruz, Red

IC Innova CESAL, Casos: Económico administrativas, pensamiento complejo y competencias. Recuperado de http://www.inno-vacesal.org/innova_public/cajon_infos/ muestra_informacion_ texto_casos

Barbosa-Chacón, J., Barbosa, J. y Rodríguez, M. (2015). Concepto, enfoque y justificación de la sistematización de experiencias educativas. Una mirada "desde" y "para" el contexto de la formación universitaria. Perfiles Educativos, 37(149), 130-149. https://doi.org/10.22201/ iisue.24486167e.2015.149.53128

Baskerville, D. y Goldblatt, H. (2009). Learning to be a critical friend: From professional indifference through challenge to unguarded conversations. Cambridge Journal of Education, 39(2), 205221. https://doi.org/10.1080/03057640902902260

Beveridge, L., Mockler, N. y Gore, J. (2017). An Australian View of the Academic Partner Role in Schools. Educational Action Research. https://doi.org/10.1080/09650792.2017.1290538

Black, P. y Wiliam, D. (2009). Developing the theory of formative assessment. Educational Assessment, Evaluation and Accountability, 21(1), 5-31. https://doi.org/10.1007/s11092-0089068-5

Cephe, P. (2009). An Analysis of the Impact of Reflective Teaching on the Beliefs of Teacher Trainees. Education and Science, 34(152), 182-191.

Çimer, A., Odabași S. y Sezen, G. (2013). How does Reflection Help Teachers to Become Effective Teachers? International Journal of Educational Research, 1(4), 133-149.

Cole, P. (2012). Linking Effective Professional Learning with Effective Teaching Practice.

Recuperado de https://ptrconsulting.com.au/wp-content/uploads/2018/03/linking_effective_ professional_learning_with_effective_teaching_practice_-_cole.pdf

Coles, J. (2017). Planting Poetry: Sowing Seeds of Creativity in a Year 5 Class. Changing English, 24(4), 386-398. https://doi.org/10.1080/1358684X.2017.1308806 
Day, C. (1999). Developing Teachers: The Challenges of Lifelong Learning. Londres: Falmer Press.

Evans, G. (2004). The Environment of Childhood Poverty. American Psychologist, 59(2), 77-92. http://dx.doi.org/10.1037/0003-066X.59.2.77

Eyzaguirre, B. y Fontaine, L. (2008). Las escuelas que tenemos. Santiago: Centro de estudios públicos. Farrell, C. (2007). Reflective language teaching: From research to practice. Nueva York: Continuum.

Fen, T., Sam, L. y Meng, C. (2017). Changes in Teachers' Reflection After Lesson Study Process. Malaysian Journal of Learning \& Instruction, 145-172. https://doi.org/10.32890/ mjli.2017.7801

Freire, P. (1999). La Educación como práctica de la libertad. México: Siglo XXI.

Ghiso, A. (1998). De la práctica singular al diálogo con lo plural. Aproximaciones a otros tránsitos y sentidos de la sistematización en épocas de globalización, Grupo Chorlavi. Recuperado de http:// www.grupochorlavi.org/webchorlavi/sistematizacion/ghiso.PDF.

Giroux, H. (1997). Los profesores como intelectuales: Hacia una pedagogía crítica del aprendizaje. España: Centro de Publicaciones del MEC. (2012). Teachers as Transformative Intellectuals. En K. Ryan y J. Cooper (Eds.), Kaleidoscope: Contemporary and Classic Readings in Education (pp. 35-40). Wadsworth Publishing.

Goikoetxea, E. y Martínez, N. (2015). Los beneficios de la lectura compartida de libros: breve revisión. Educación XXI, 18(1), 303-324. https://doi.org/10.5944/educxx1.18.1.12334

Golby, M. y Appleby, R. (1995). Reflective Practice Through Critical Friendship: Some Possibilities. Cambridge Journal of Education, 25(2), 149-160. https://doi.org/10.1080/0305764950250203

Gómez, V., Guerra, P., Santa Cruz, J., Thomsen, P., Rodríguez, C. y Beas, J. (2012). Díadas reflexivas colaborativas: Construyendo nuevos significados sobre aprendizaje y enseñanza. Electronic Journal of Research in Educational Psychology, 10(1), 271-310. https://doi.org/10.25115/ejrep. v10i26.1495

Gorichon, S., Salas, M., Araos, M. J., Yáñez, M., Rojas-Murphy, A. y Jara-Chandía, G. (2020). Prácticas de mentoría para la inducción de docentes principiantes: Análisis de cuatro casos chilenos al inicio del proceso. Calidad en la educación, (52), 12-48. http://dx.doi.org/10.31619/ caledu.n52.824

Guiso, A. (2001). Sistematización de experiencias en Educación popular. En Foro: Los contextos Actuales de la Educación Popular. Medellín.

Gurr, D. y Drysdale, L. (2018). System Leadership and School Leadership. Research in Educational Administration \& Leadership (REAL), 3(2), 207-229. https://doi.org/10.30828/real/2018.2.4

Hart, D. y Risley, T. (1995). Meaningful Differences. Baltimore: Paul H. Brooks.

Hattie, J., Biggs, J. y Purdie, N. (1996). Effects of Learning Skills Interventions on Student Learning: A Meta-Analysis. Review of Educational Research, 66(2), 99-136. http://dx.doi. org/10.2307/1170605

Hatton, N. y Smith, D. (1995). Reflection in Teacher Education: Towards Definition and Implementation. Teaching and Teacher Education, 11(1), 33-49. https://doi.org/10.1016/0742051X(94)00012-U

Herrada-Valverde, G. y Herrada, R. (2017). Análisis del proceso de comprensión lectora de los estudiantes desde el modelo construcción-integración. Perfiles educativos, 39(157), 181-197. https://doi.org/10.22201/iisue.24486167e.2017.157.58448

Hill, G. (2002). Critical friendship. Brisbane: Mottram D'Hill \& Associates.

Jara, O. (1998). Para sistematizar experiencias. San José, CR: Alforja.

Jay, J. y Johnson, K. (2002). Capturing Complexity: A Typology of Reflective Practice for Teacher Education. Teaching and Teacher Education, 18(1), 73-85. https://doi.org/10.1016/S0742051X(01)00051-8

Kiewkor, S., Wongwanich, S. y Piromsombat, C. (2014). Empowerment of Teachers through Critical Friend Learning to Encourage Teaching Concepts. Procedia - Social and Behavioral Sciences, 116, 4626-4631. https://doi.org/10.1016/j.sbspro.2014.01.997 
Korthagen, F., Kessels, J., Koster, B., Lagerwerf, B. y Wubbels, T. (2001). Linking Practice and Theory: The Pedagogy of Realistic Teacher Education. Nueva Jersey: Lawrence Erlbaum Associates.

Landry, S., Smith, K. E., Swank, P., Assel, M. A. y Vellet, S. (2001). Does Early Responsive Parenting Have a Special Importance for Children's Development Or Is Consistency Across Early Childhood Necessary? Developmental Psychology, 37(3), 387-403. http://dx.doi.org/10.1037/00121649.37.3.387

Larrivee, B. (2008). Development of a Tool to Assess Teachers' Level of Reflective Practice. Reflective Practice: International and Multidisciplinary Perspectives, 9(3), 341-360. https://doi. org/10.1080/14623940802207451

Leiva, M., Montecinos, C. y Aravena, F. (2017). Liderazgo pedagógico en directores nóveles en Chile: Prácticas de observación de clases y retroalimentación a profesores. RELIEVE-Revista Electrónica de Investigación y Evaluación Educativa, 22(2). http://dx.doi.org/10.7203/relieve.22.2.9459

Loh, J., Hong, H. y Koh, E. (2018). Transforming Teaching Through Collaborative Reflection: A Singaporean Case Study. Malaysian Journal of ELT Research, 13(1), 1-11.

Lotter, C. y Miller, C. (2017). Improving Inquiry Teaching Through Reflection on Practice. Research in Science Education, 47(4), 913-942. https://doi.org/10.1007/s11165-016-9533-y

Mena, J., Sánchez, E. y Tillema, H. (2011). Promoting Teacher Reflection: What Is Said to Be Done. Journal of Education for Teaching, 37(1), 21-36. https://doi.org/10.1080/02607476.2011.538269

Muller, M., Volante, P., Grau, V. y Preiss, D. (2014). Desarrollo de habilidades de observación en la formación de liderazgo escolar a través de videos de clases. Psykhe (Santiago), 23(2), 1-12. http:// dx.doi.org/10.7764/psykhe.23.2.713

Nelson, K.; Welsh, J.; Vance, E. y Greenberg, M. (2011). Language Delays of Impoverished Preschool Children in Relation to Early Academic and Emotion Recognition Skills. First Language, 31(2), 164-194. https://doi.org/10.1177/0142723710391887

Petroelje, E., Frambaugh-Kritzer, C., Freese, A. y Persson, A. (2018). What makes a critical friend? En D. Garbett \& A. Ovens (Eds.), Pushing boundaries and crossing borders: Self-study as a means for researching pedagogy (pp. 147-154). Self-Study of Teacher Education Practices (S-STEP) - a special interest group of AERA.

Programa de las Naciones Unidas Para el Desarrollo (2017). Desiguales. Orígenes, cambios y desafíos de la brecha social en Chile. Recuperado de http://www.cl.undp.org/.

Pujato, B. (2011). El ABC de la alfabetización ¿Cómo enseñamos a leer y a escribir? Santa Fé: Homo Sapiens Ediciones.

Redondo, S. y Navarro, A. (2007). Sistematización de un proyecto de educación en valores. Revista Complutense de Educación, 18(2), 163-180.

Restrepo, M. y Tabares, L. (2000). Métodos de investigación en educación. Revista de Ciencias Humanas, 21, 1-10.

Richards, J. y Lockhart, C. (1994). Reflective Teaching in Second Language Classrooms.

Cambridge: CUP.

Risko, V., Vukelich, C. y Roskos, K. (2009). Detailing Reflection Instruction: The Efficacy of a Guided Instructional Procedure on Prospective Teachers' Pedagogical Reasoning. Action in Teacher Education, 31(2), 47-60. https://doi.org/10.1080/01626620.2009.10463517

Rosas, R. y Santa Cruz, C. (2013). Dime en qué colegio estudiaste y te diré qué CI tienes: Radiografía al desigual acceso al capital cognitivo en Chile. Santiago: Ediciones UC.

Sánchez, A. (2010). El artículo sistematización de experiencias: Construcción de sentido desde una perspectiva crítica. Revista Virtual Universidad Católica del Norte, (29), 1-7.

Schön, D. (1987). Educating the Reflective Practitioner. San Francisco, C.A.: Jossey-Bass. https://doi. org/10.1002/chp.4750090207

. (1993). Learning to Design and Designing to Learn. Nordik Arkitekturforskning, 6(1).

. (2017). The Reflective Practitioner: How Professionals Think in Action. Londres: Routledge. https://doi.org/10.4324/9781315237473 
Snow, C., Tabors, P. y Dickinson, D. (2001). Language Development in the Preschool Years. En D. K. Dickinson y P. O. Tabors (Eds.), Beginning Literacy with Language: Young Children Learning at Home and School (pp. 1-25). Baltimore, MD: Brookes.

Snow, C.; Burns, M. y Griffin, P. (1998). Preventing Reading Difficulties in Young Children. Washington, DC: National Academy Press. Disponible en: http://www.nap.edu/catalog/6023.html.

Sparks-Langer, G. y Colton, A. (1991). Synthesis of Research on Teachers' Reflective Thinking. Reflective Pedagogical Thinking: How Can We Promote It and Measure It? Educational Leadership, 48(6), 37-44. https://doi.org/10.1177/002248719004100504

Stokes, L. (2003). La indagación como base de la formación del profesorado y la mejora de la educación. Barcelona: Octaedro.

Subsecretaría para la Educación Parvularia (2018). Bases curriculares Educación Parvularia. Recuperado de: https://bibliotecadigital.mineduc.cl/

Swaffield, S. (2005). No sleeping partners: relationships between head teachers and critical friends. School Leadership \& Management, 25(1), 43-57. https://doi.org/10.1080/1363243052000317082 (2007). Light touch critical friendship. Improving Schools, 10(3), 205-219. https://doi. org/10.1177/1365480207077845

Swars, S., Meyers, B., Schafer, N., Kavanagh, K. y Haardoerfer, R. (2018). Becoming Critical Friends: Developmental Portraits of Three Professional Learning Communities. National Teacher Education Journal, 11(2), 23-39.

Swartz, S. (2010). Cada niño un lector. Estrategias innovadoras para enseñar a leer y escribir. Ediciones UC.

Timperley, H. (2011). A background paper to inform the development of a national professional development framework for teachers and school leaders. Recuperado de: https://enable.eq.edu. au/Supportandresources/Formsanddocuments/Documents/background-paper.pdf

Van Manen, M. (1977). Linking Ways of Knowing with Ways of Being Practical. Curriculum Inquiry, 6, 205-228. https://doi.org/10.1080/03626784.1977.11075533

Vasco, C. (2008). Sistematizar o no, he ahí el problema. Revista Internacional Magisterio. Educación y Pedagogía, (23), 19-21.

Watling, R., Hopkins, D., Harris, A. y Beresford, J. (1998). Between the devil and the deep blue sea? Implications for school and LEA development following an accelerated inspection programme. En L. Stoll \& K. Myers (Eds.), No quick fixes: Perspectives on schools in difficulty (pp. 47-63). London: Falmer.

Weizman, Z. y Snow, C. (2001). Lexical Output as Related to Children's Vocabulary Acquisition: Effects of Sophisticated Exposure and Support for Meaning. Developmental Psychology, 37, 265279. https://doi.org/10.1037/0012-1649.37.2.265

Wennergren, A. (2016). Teachers as learners - with a little help from a critical friend. Educational Action Research, 24(2), 260-279. https://doi.org/10.1080/09650792.2015.1058170

Whitehurst, G. y Fischel, J. (2000). A Developmental Model of Reading and Language Impairments Arising in Conditions of Economic Poverty. En D. Bishop y L. Leonard (Eds.), Speech and Language Impairments in Children: Causes, Characteristics, Intervention and Outcome (pp. 5371). Hove: Psychology Press.

Yu, W. y Chiu, M. (2019). Influences on the Reflection Quality of Journal Writing: An Exploratory Study. Reflective Practice, 20(5), 584-603. https://doi.org/10.1080/14623943.2019.1651712

Zeichner, K. (1993). El maestro como profesional reflexivo. Cuadernos de Pedagogía, 220, 44-45.

Zeichner, K. y Liston, D. (1985). Theory and Practice in the Evolution of an Inquiry-Oriented Student Teaching Program. En Annual Meeting of the American Educational Research Association, Chicago. https://doi.org/10.1080/02671522.2013.772222 . (2014). Reflective Teaching: An Introduction. Nueva York: Routledge. 
